\title{
Neratinib overcomes trastuzumab resistance in HER2 amplified breast cancer
}

\author{
Alexandra Canonici ${ }^{1, *}$, Merel Gijsen ${ }^{2,}{ }^{*}$, Maeve Mullooly4, Ruth Bennett ${ }^{2}$, Noujoude \\ Bouguern $^{2}$, Kasper Pedersen ${ }^{1}$, Neil A O'Brien ${ }^{5}$, Ioannis Roxanis ${ }^{6}$, Ji-Liang $\mathbf{L i}^{3}$, \\ Esther Bridge ${ }^{3}$, Richard Finn ${ }^{5}$, Dennis Slamon ${ }^{5}$, Patricia McGowan ${ }^{4}$, Michael $\mathrm{J}$. \\ Duffy $^{4}$, Norma O'Donovan ${ }^{1, *}$, John Crown ${ }^{1,4, *}$ and Anthony Kong ${ }^{2, *}$ \\ ${ }^{1}$ National Institute for Cellular Biotechnology, Dublin City University, Dublin, Ireland; \\ ${ }^{2}$ Human Epidermal Growth Factor Group, University of Oxford, UK \\ ${ }^{3}$ Growth Factor Group, Department of Oncology, Weatherall Institute of Molecular Medicine, University of Oxford, UK; \\ ${ }^{4}$ Clinical Research Centre, St. Vincent's University Hospital, and UCD School of Medicine and Medical Science, Conway \\ Institute, University College Dublin, Dublin, Ireland; \\ ${ }^{5}$ Division of Hematology-Oncology, Department of Medicine, David Geffen School of Medicine, University of California at Los \\ Angeles, Los Angeles, California; \\ ${ }^{6}$ Department of Cellular Pathology, Oxford University Hospitals and Oxford Biomedical Research Centre, Oxford, United \\ Kingdom. \\ * These authors contributed equally \\ Correspondence to: Anthony Kong, email: anthony.kong@oncology.ox.ac.uk
}

John Crown, email: john.crown@icorg.ie

Norma O'Donovan, email: norma.odonovan@dcu.ie

Keywords: breast cancer, HER2/ErbB2, trastuzumab (Herceptin), neratinib, panHER inhibitor

Received: July 6, $2013 \quad$ Accepted: July 24, $2013 \quad$ Published: July 25, 2013

This is an open-access article distributed under the terms of the Creative Commons Attribution License, which permits unrestricted use, distribution, and reproduction in any medium, provided the original author and source are credited.

ABSTRACT:

Trastuzumab has been shown to improve the survival outcomes of HER2 positive breast cancer patients. However, a significant proportion of HER2-positive patients are either inherently resistant or develop resistance to trastuzumab. We assessed the effects of neratinib, an irreversible panHER inhibitor, in a panel of $\mathbf{3 6}$ breast cancer cell lines. We further assessed its effects with or without trastuzumab in several sensitive and resistant breast cancer cells as well as a BT474 xenograft model. We confirmed that neratinib was significantly more active in HER2-amplified than HER2 non-amplified cell lines. Neratinib decreased the activation of the 4 HER receptors and inhibited downstream pathways. However, HER3 and Akt were reactivated at 24 hours, which was prevented by the combination of trastuzumab and neratinib. Neratinib also decreased pHER2 and pHER3 in acquired trastuzumab resistant cells. Neratinib in combination with trastuzumab had a greater growth inhibitory effect than either drug alone in 4 HER2 positive cell lines. Furthermore, trastuzumab in combination with neratinib was growth inhibitory in SKBR3 and BT474 cells which had acquired resistance to trastuzumab as well as in a BT474 xenograft model. Innately trastuzumab resistant cell lines showed sensitivity to neratinib, but the combination did not enhance response compared to neratinib alone. Levels of HER2 and phosphoHER2 showed a direct correlation with sensitivity to neratinib. Our data indicate that neratinib is an effective anti-HER2 therapy and counteracted both innate and acquired trastuzumab resistance in HER2 positive breast cancer. Our results suggest that combined treatment with trastuzumab and neratinib is likely to be more effective than either treatment alone for both trastuzumab-sensitive breast cancer as well as HER2-positive tumors with acquired resistance to trastuzumab. 


\section{INTRODUCTION}

HER2 is a member of the human epidermal growth factor receptor (HER) family which also includes EGFR (HER1), HER3 and HER4 [1]. The HER proteins are receptor tyrosine kinases which consist of an extracellular domain, an $\alpha$-helical transmembrane region and an intracellular tyrosine kinase domain [2]. The crystal structure of HER2 shows that the extracellular domain is constitutively in an 'open' conformation, ready for dimerization [3]. Although HER2 has no known ligand, it is the preferred heterodimerization partner of the other HER receptors and is involved in the lateral transmission of signals between other HER family receptors [4]. The HER2/HER3 dimer is considered to be the most potent with regards to strength of interaction, ligand-induced tyrosine phosphorylation and downstream signaling $[5$, 6]. HER 2 signaling promotes cell proliferation via the RAS-ERK pathway and inhibits cell death via the PI3KAkt-mTOR pathway [7]. Over-expression of HER2 occurs in approximately $20 \%$ of breast cancers and is associated with a poor prognosis $[8,9]$.

Trastuzumab is a humanized monoclonal antibody which binds to extracellular domain IV of HER2. It has been shown to increase survival in HER2 positive metastatic and early breast cancer patients, especially when given in combination with chemotherapy $[10,11]$. Trastuzumab is thought to exert its anti-tumor activity partly by accelerating the internalization and degradation of HER2 and thus blocking downstream signaling. In addition, it may also act by mediating antibody-dependentcellular cytotoxicity [12]. However, many patients do not respond to trastuzumab and the majority who initially respond, progress within a year of initiating therapy [13]. Understanding the mechanisms responsible for resistance to trastuzumab is therefore crucial for the development of new therapeutic strategies and improving patient outcome.

Based on preclinical studies, mechanisms of primary and acquired resistance to trastuzumab include (i) activation of PI3K/Akt signaling due to PTEN loss or PI3KCA mutations $[14,15]$, (ii) the presence of p95HER2, a truncated form of HER2 [16]; (iii) interaction of HER2 with other receptors such as IGF-IR and c-Met $[17,18]$ and (iv) activation of HER receptors by an Akt negative feedback loop [19]. Other proposed mechanisms include the constitutive activation of the autophagy-related gene 12 (ATG12) [20], the presence of trastuzumab-refractory breast cancer stem cells (CSCs) [21], and the steric hindrance caused by association of HER2 with other cell surface signaling proteins, i.e. integrins $\beta 1, \mathrm{CD} 44, \mathrm{MUC1}$ and MUC4 [22].

In an attempt to circumvent resistance to trastuzumab, anti-HER2 tyrosine kinase inhibitors (TKIs) were introduced. The first TKI to show activity in HER2 positive breast cancer patients was the dual EGFR/HER2 reversible TKI, lapatinib [23]. In patients who were resistant to trastuzumab, the combination of lapatinib with capecitabine increased median time to progression compared to capecitabine alone [23]. As a result, lapatinib with capecitabine is currently licensed for use in patients who have previously failed trastuzumab. Clinical trials have shown that the addition of trastuzumab and lapatinib to chemotherapy achieved a higher pathological complete response than either trastuzumab or lapatinib alone [24, 25].

To further enhance HER2 inhibition, irreversible TKIs, such as neratinib, afatinib and dacomitinib have been developed. Neratinib, is an irreversible inhibitor of EGFR, HER2 and HER4 tyrosine kinase activity [26] shown to have promising preclinical activity against HER2-overexpressing cell lines [27]. Indeed, it is currently undergoing several phase 3 clinical trials [28, 29]. Since we have previously shown that trastuzumabinduced activation of all HER receptors may contribute to trastuzumab resistance [19], we assessed the effects of neratinib, to determine if it can improve response and overcome resistance to trastuzumab, in sensitive and resistant HER2 amplified breast cancer cells.

\section{RESULTS}

\section{Neratinib sensitivity in a panel of breast cancer cell lines}

We determined sensitivity to neratinib in a panel of 36 breast cancer cell lines, including HER2 positive, luminal and basal-like cell lines (Figure 1A left panel, Supplementary Table 1). The HER2 positive cell lines $(\mathrm{n}=12)$ were significantly more sensitive to neratinib, than either the triple negative $(\mathrm{n}=15, \mathrm{p}=0.0002)$ or luminal cell lines $(n=9, p=0.0055)$ (Figure 1A, right panel). One luminal cell line however, MDA-MB-175, showed sensitivity to neratinib $\left(\mathrm{IC}_{50}\right.$ value $\left.<0.001 \mu \mathrm{M}\right)$, while one of the HER2 positive cell lines, UACC-732, was relatively insensitive to neratinib $\left(\mathrm{IC}_{50}\right.$ value $\left.=0.65 \mu \mathrm{M}\right)$. The $\mathrm{IC}_{50}$ values for neratinib were lower than those previously published for lapatinib in the panel of HER2 positive cell lines [30]. The results were also confirmed by direct comparison of the two drugs in SKBR3 and BT474 cells, and both cell lines showed greater sensitivity to neratinib than lapatinib (data not shown).

\section{Neratinib decreases pHER2 in a dose-dependent manner in HER2 amplified breast cancer cells}

As the HER2 positive cell lines were significantly more sensitive to neratinib, we investigated the effect of neratinib on HER2 signalling in two HER2 positive breast cell lines. One hour of neratinib $(2 \mathrm{nM})$ treatment did not decrease pHER2 levels despite inhibition of pAkt 
and pERK (Figure 1B). However, pHER2 was inhibited after 24 hours (Figure 1B). A dose dependent inhibition of pHER2 was observed with increasing concentrations of neratinib in both cell lines (Figure 1B). Although total HER2 levels were not altered by treatment with neratinib for 1 hour, by 24 hours HER2 level was reduced in response to $50 \mathrm{nM}$ neratinib in SKBR3 and was undetectable in BT474 cells.

Reactivation of pERK was observed after 24 hours of neratinib treatment in SKBR3 cells, although the highest concentration of neratinib $(50 \mathrm{nM})$ inhibited this reactivation (Figure 1B). The reactivation of $\mathrm{pERK}$ was not seen in BT474 cells, which are more sensitive than SKBR3 cells (Figure 1B). The results suggest that neratinib effectively inhibits HER2 activation and downstream signaling in HER2 positive breast cell lines.

\section{Combined treatment with neratinib and} trastuzumab has an additive effect

To assess the effect of trastuzumab with neratinib, SKBR3 and BT474 cells were treated with $40 \mu \mathrm{g} /$ $\mathrm{ml}$ trastuzumab, $2 \mathrm{nM}$ neratinib or the combination for six days. The combination treatment was significantly more effective in reducing cell numbers compared to trastuzumab alone $(\mathrm{p}<0.001)$ or neratinib alone $(\mathrm{p}<$ 0.05 ) in both cells lines (Figure 2A). To understand the enhanced response to the combination, a time-course experiment was performed to assess the effect of the combination on HER receptor activation and downstream signaling. Figure $2 \mathrm{~B}$ shows the results after three days of treatment in the SKBR3 cells (data for BT474 cells are not shown as there were insufficient cells left after three days of the combination treatment). Trastuzumab
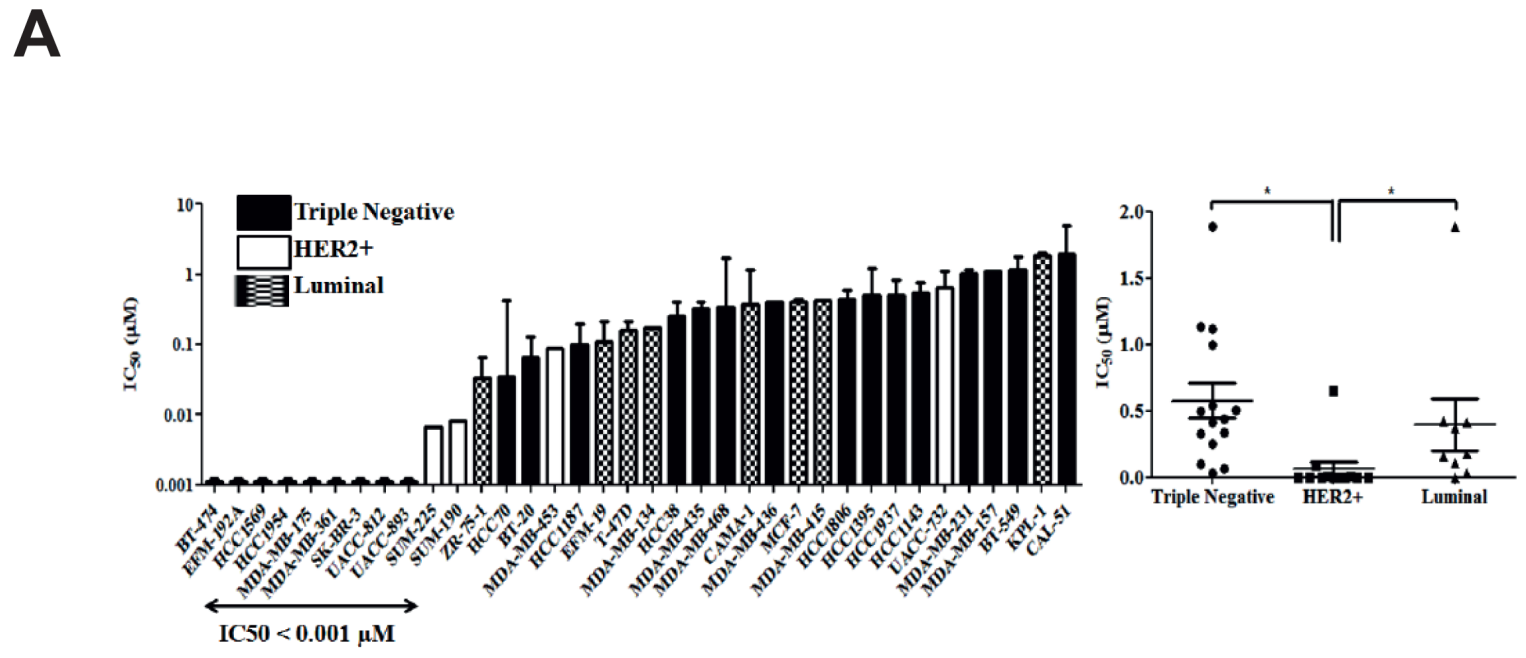

B
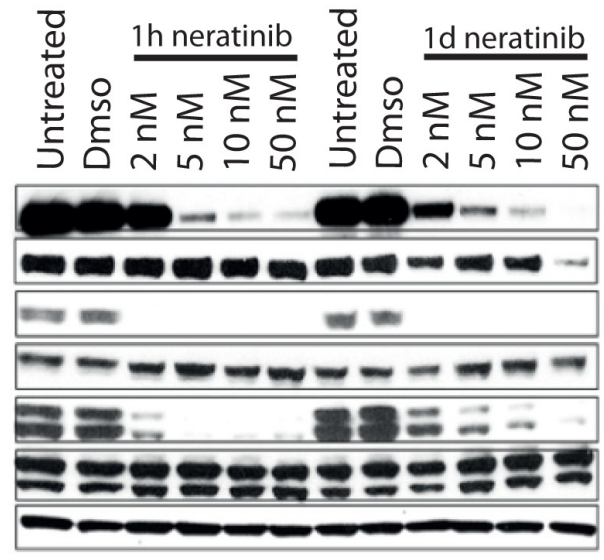

SKBR3

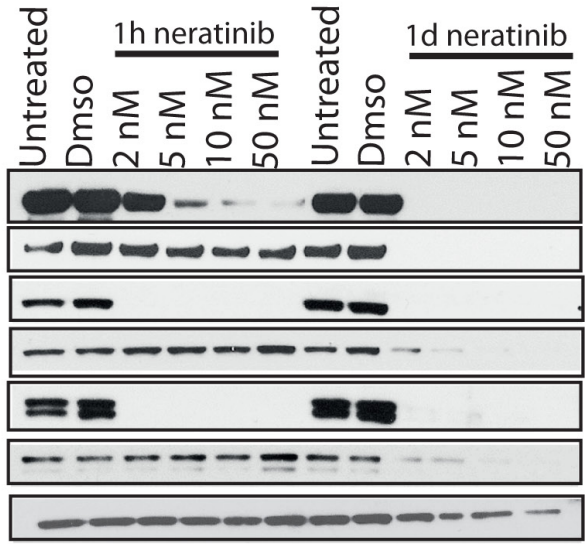

BT474

Figure 1: Neratinib is most effective in HER2 positive breast cell lines and reduces HER2 phosphorylation. A) Neratinib $\mathrm{IC}_{50}$ values $(\mu \mathrm{M})$ and breast cancer cell type. Cell lines are color coded by subtype: white bars - HER2 amplified; black bars - triple negative; stripes - luminal. Differences between the cell line subtypes were analysed by Mann-Whitney U test. * p <0.05. B) BT474 (right) and SKBR3 (left) cell were treated for 1 hour or 1 day with increasing concentrations of neratinib. After lysis, protein levels were assessed using western blotting techniques. 
decreased pHER3 and pAkt only minimally after 1 hour and did not decrease pEGFR, pHER2, pHER4 or pERK at the timepoints tested (Figure 2B and Supplementary Figure 1). In contrast, 1-hour neratinib treatment inhibited phosphorylation of EGFR, HER2, HER3 and HER4 as well as pAkt and pERK levels (Figure 2B and Supplementary Figure 1). However, reactivation of HER3 and Akt phosphorylation was observed after 24 hours (Figure 2B and Supplementary Figure 1). The combination of trastuzumab and neratinib prevented reactivation of pHER3 and pAkt and downregulated EGFR and HER2 at 3 days (Figure 2B and Supplementary Figure 1).

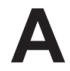

BT474

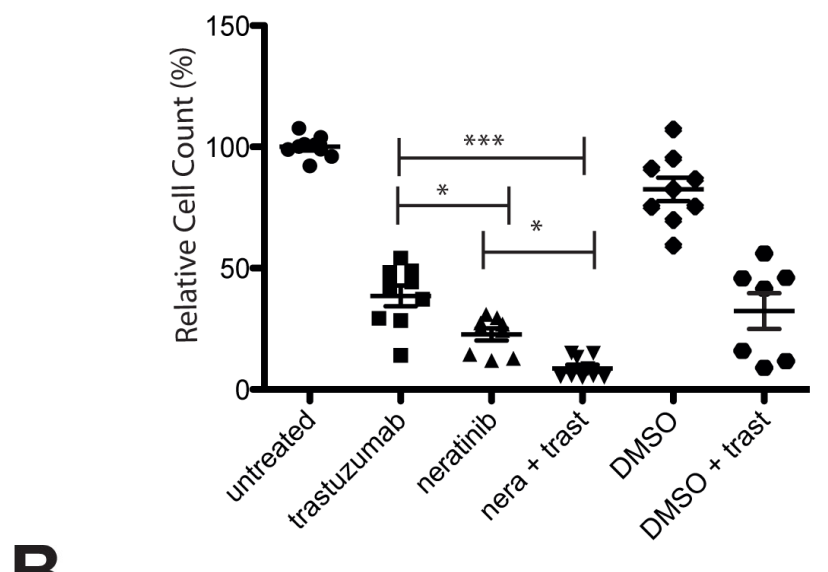

B

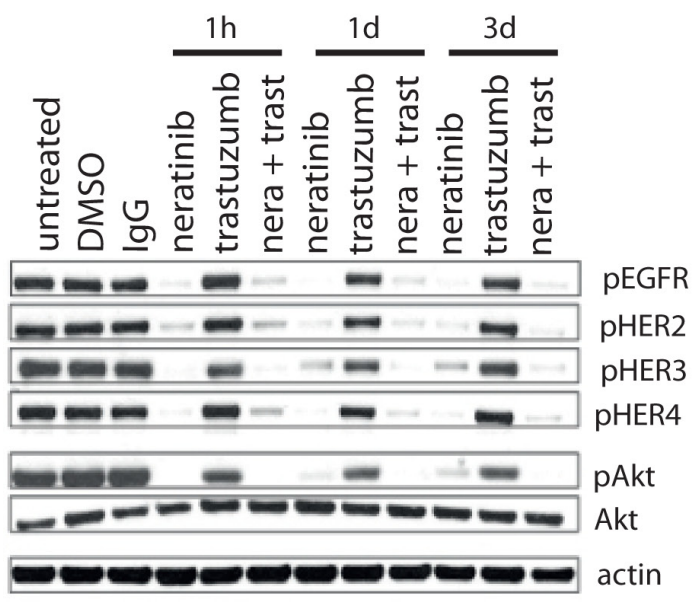

Neratinib is effective in acquired trastuzumab resistant HER2 amplified cells

We tested the effect of neratinib on acquired trastuzumab resistant BT474 (BT474R) and SKBR3 (SKBR3R) cells. With increasing doses, neratinib inhibited pHER2 and pHER3 as well as downstream pathways in both cell lines at 1 hour and 1 day (Figure $3 \mathrm{~A}$ ). We also assessed the effect of trastuzumab withdrawal and/ or neratinib treatment in resistant cells. In the BT474R and SKBR3R cells, withdrawal of trastuzumab increased the cell count significantly, compared to trastuzumab replacement or continuous treatment with trastuzumab
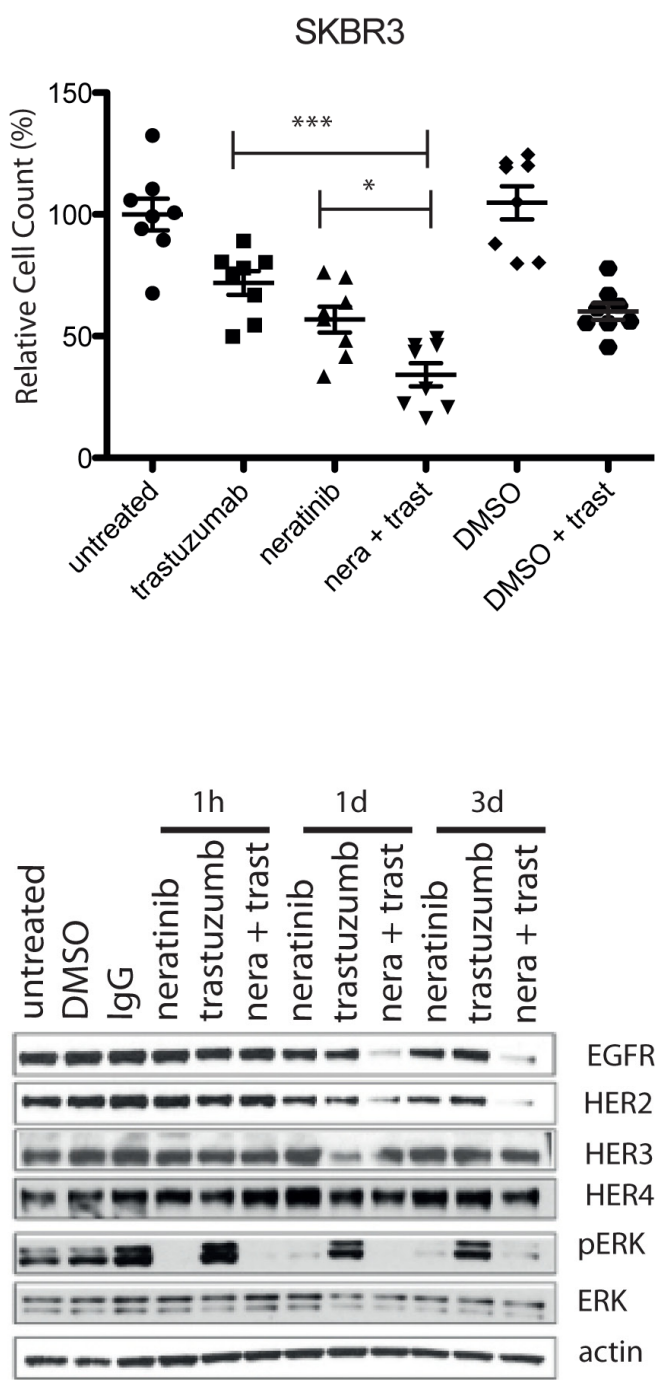

Figure 2: Combination of neratinib and trastuzumab has an additive effect and prevents re-activation of pHER3 and pAkt. A) BT474 (left) and SKBR3 (right) cells are treated for 5 days with either $40 \mu \mathrm{g} / \mathrm{ml}$ trastuzumab or $2 \mathrm{nM}$ neratinib or their combination ( $\mathrm{n}=3$, both technical and biological replicates are represented in the figures). DMSO is used as a vehicle control for neratinib. Cells were trypsinized and counted using a cell counter. The differences in means of the cell count between the groups were analysed by Anova with Bonferroni's multiple comparison test and statistically significant changes were represented by asterisks $(*, \mathrm{P} \leq 0.05 ; * * *, \mathrm{P} \leq$ 0.001). B) SKBR3 cells were treated with $2 \mathrm{nM}$ neratinb, $40 \mu \mathrm{g} / \mathrm{ml}$ trastuzumab or their combination for the indicated times before the cells were lysed and analysed by western blot. 
(Figure 3B). Neratinib monotherapy decreased cell numbers to a greater extent than trastuzumab replacement, in both resistant cell lines (Figure 3B). Furthermore, the combination of trastuzumab and neratinib had a greater growth inhibitory effect than either drug alone, with or without trastuzumab withdrawal in SKBR3R (Figure 3B).

\section{Combined treatment with neratinib and trastuzumab in a panel of HER2 amplified cell lines}

Based on the additive interaction between neratinib and trastuzumab observed in the SKBR3 and BT474 cell lines, we extended the analysis of the combination treatment to 7 additional HER2 amplified breast cancer cell lines, including cell line models of innate trastuzumab resistance. In the MDA-MB-361 and EFM-192-A cell lines, which are moderately sensitive to trastuzumab, the combination of neratinib and trastuzumab showed greater inhibition of growth than either of the drugs alone (Figure 4A). However in the trastuzumab-resistant cell lines (JIMT1, MDA-MB-453, HCC1419, HCC1954, UACC732) the combination treatment showed no enhancement compared to neratinib alone (Figure 4B and Supplementary Figure 2).

\section{A}
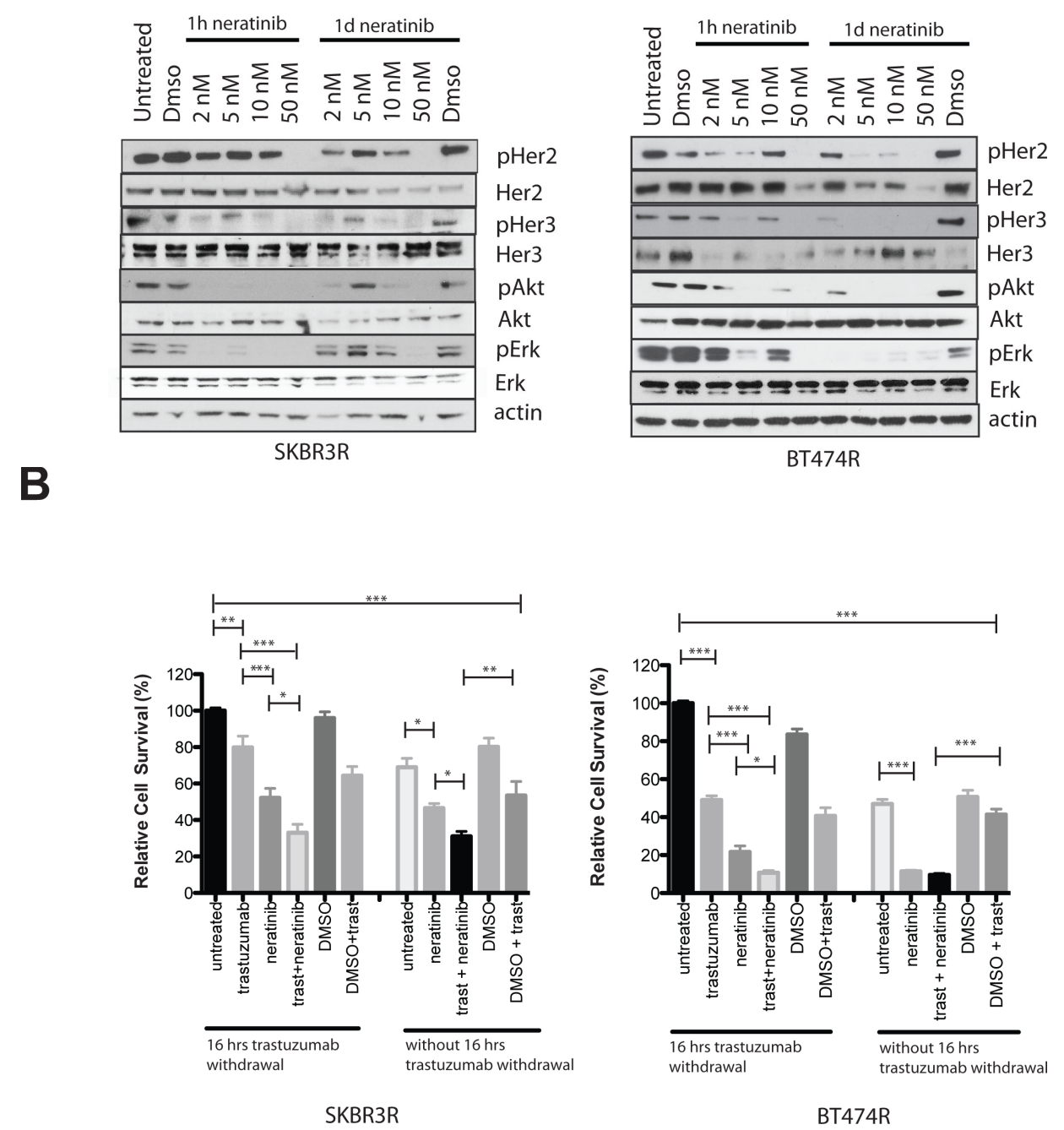

Figure 3: Trastuzumab resistant cells are sensitive to neratinib treatment. A) Trastuzumab resistant SKBR3 (SKBR3R, left) or BT474R (right) cells were treated for 1 hour or 1 day with increasing doses of neratinib. The cells were continuously kept in media with $40 \mu \mathrm{g} / \mathrm{ml}$ trastuzumab. Cells were lysed and protein levels analysed by western blot. B) SKBR3R (left) and BT474R (right) cells were treated for 5 days with $2 \mathrm{nM}$ of neratinib, $40 \mathrm{ug} / \mathrm{ml}$ trastuzumab or their combination. Cells were trypsinized and counted using a cell counter. Cells were either seeded out with $40 \mu \mathrm{g} / \mathrm{ml}$ trastuzumab in the media or plated out overnight without trastuzumab for 16 hours in the media before treatment was commended the next day. The differences in means of the cell count between the groups were analysed by Anova with Bonferroni's multiple comparison test and statistically significant changes were represented by asterisks $(*, \mathrm{P} \leq 0.05 ; * *, \mathrm{P} \leq$ $0.01 ; * * *, \mathrm{P} \leq 0.001)$. 


\section{Response to neratinib correlates with HER2 and} pHER2 in HER2 amplified breast cancer cell lines

In order to identify potential predictive biomarkers for neratinib sensitivity in HER2 positive breast cancer, we correlated the neratinib $\mathrm{IC}_{50}$ values with a panel of potential biomarkers previously measured by O'Brien et al [30] to determine their relationship with response/ resistance to lapatinib and/or trastuzumab. In the panel of 11 HER 2 positive breast cancer cell lines, higher baseline levels of both HER2 and phosphorylated HER2 significantly correlated with response to neratinib $(p=0.038$ and 0.042 respectively) (Figure 5A). Neratinib sensitivity was not significantly associated with p95HER2, EGFR, HER3, Akt, ERK, PTEN, PI3K mutation status or ER status (Supplementary Table 2).

\section{Correlation between the effect of neratinib on cell signaling and biomarkers}

In order to examine potential pharmacodynamic biomarkers of response to neratinib, we tested the effects of neratinib (200 nM) on HER2 and downstream signalling in a panel of HER2 amplified cell lines, with varying sensitivity to neratinib (Figure 5B). In all cell lines tested, neratinib significantly reduced phosphorylation of HER2, although the level of reduction did not correlate with sensitivity to neratinib (Figure 5C). Neratinib inhibited phosphorylation of Akt and ERK to a greater extent in cell lines which are more sensitive to neratinib (pAkt: $\mathrm{p}=0.026$; $\mathrm{pERK}$ : $\mathrm{p}=0.012$ ).

$\mathbf{A}$

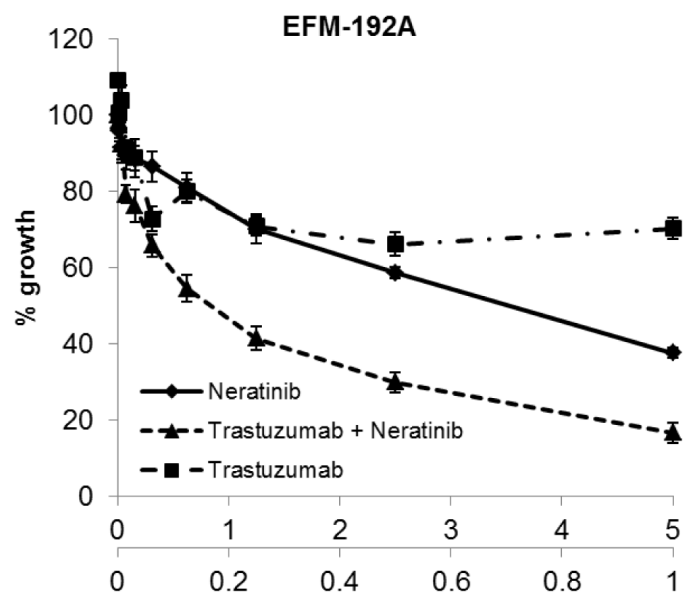

B

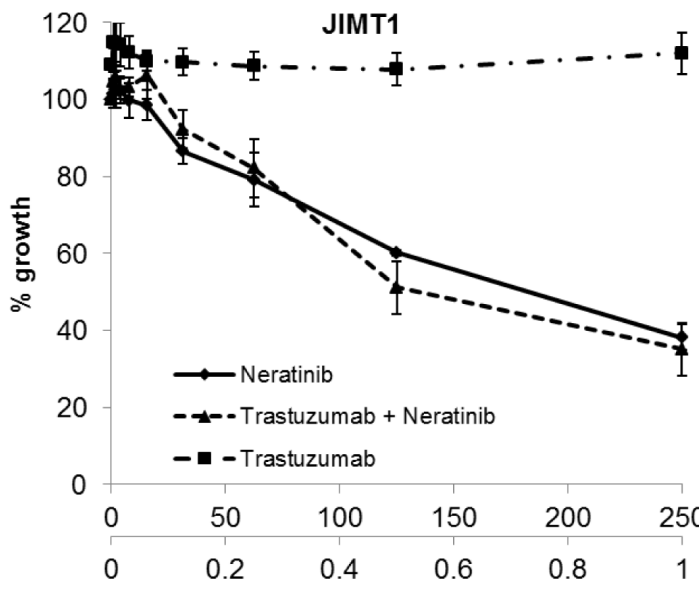

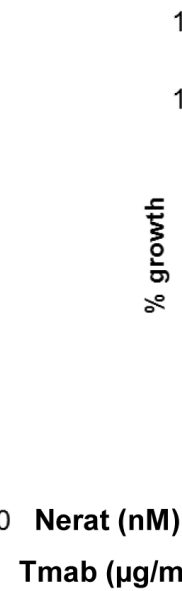

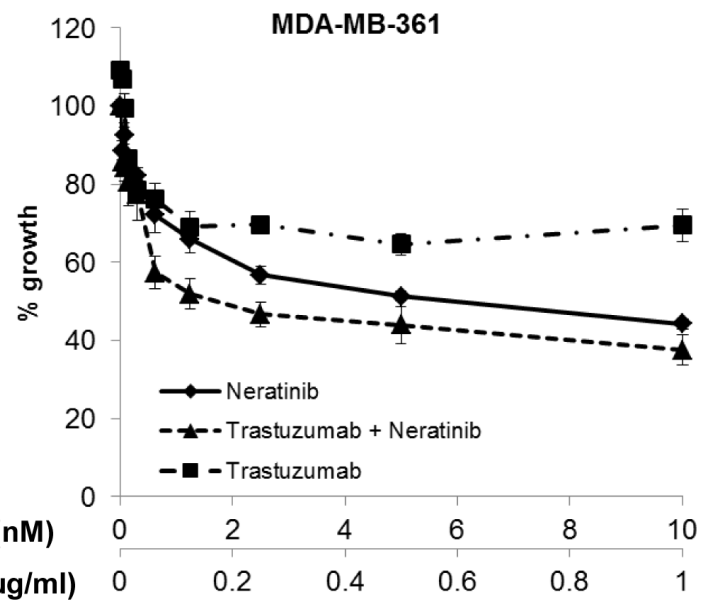

\begin{tabular}{|c|c|c|c|}
\hline Tmab (ua/ml) & 0 & 02 & \\
\hline
\end{tabular}

Figure 4: Combined neratinib and trastuzumab treatment in cell line models with varying trastuzumab sensitivity and resistance. Sensitivity to trastuzumab and neratinib in A) two trastuzumab moderately sensitive and B) two innately trastuzumab resistant HER2 positive breast cancer cell lines. Cells were treated with neratinib alone, trastuzumab alone or the combination at a fixed ratio for 5 days. 


\section{Combined treatment with trastuzumab and neratinib is additive in a BT474 xenograft model}

We further examined the effect of neratinib and/or trastuzumab in a BT474 xenograft model and showed that the combination treatment resulted in the greatest tumour inhibition (Figure 6A), correlated with the final tumor volume in vivo among the four groups (vehicle control vs combination group, $\mathrm{p}<0.05$; all other comparisons, $\mathrm{p}>0.05$ ) (Supplementary Figure $3 \mathrm{~A}$ left panel). The combination treatment also resulted in the smallest tumor weight ex-vivo (vehicle control vs combination group, $\mathrm{p}<$ 0.05 ; all other comparisons, $\mathrm{p}>0.05$ ) (Supplementary Figure 3A right panel) and with higher percentage of connective tissue ex-vivo compared to vehicle control ( $\mathrm{p}<$ $0.001)$ or neratinib alone $(\mathrm{p}<0.01)$ (Figure 6B).

Immunohistochemical (IHC) staining in the xenograft tumors showed no statistically difference in the levels of membrane HER2 and pHER2 between any of the groups although the trastuzumab and neratinib combination treatment showed the lowest IRS scoring for pHER2 staining (Figure 6C and 6D). In contrast to HER2, staining for pHER3 was weak but the lowest IRS scoring was seen in the combination arm (Supplementary Figure 3B). Consistent with the cell line data, neratinib and trastuzumab inhibited pAkt to a greater extent than trastuzumab monotherapy but not neratinib monotherapy (Figure 6E and Supplementary Figure 3C). Neratinib treatment showed little effect on ERK phosphorylation whereas trastuzumab alone and the combination treatment decreased pERK staining in the xenograft tumors (Figure 6F and Supplementary Figure 3C). However, the differences in pHER3, pAkt and pERK IHC staining were not statistically significant.

A
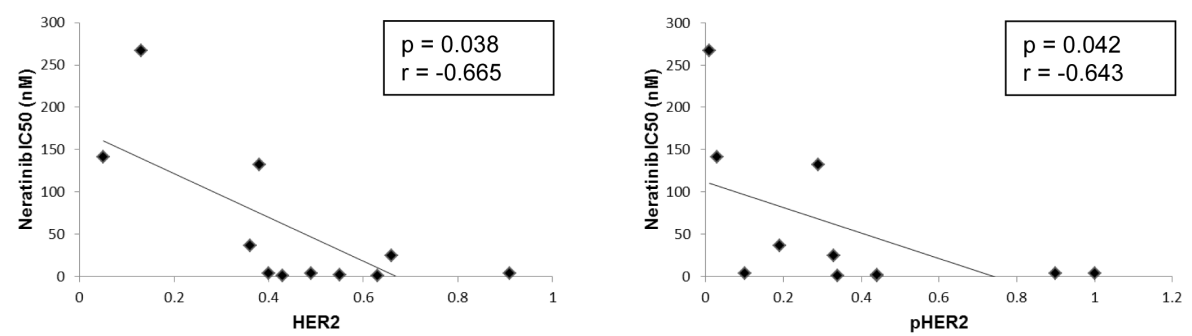

B

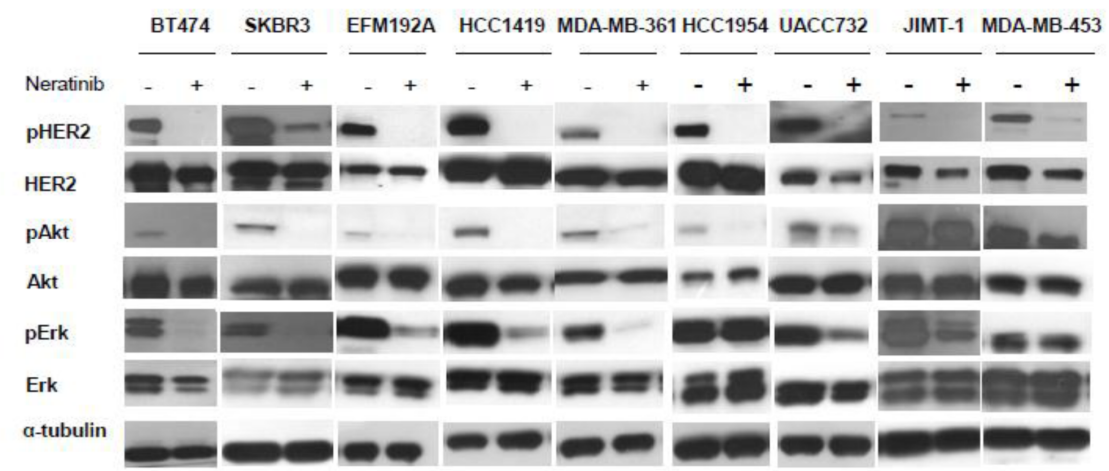

C
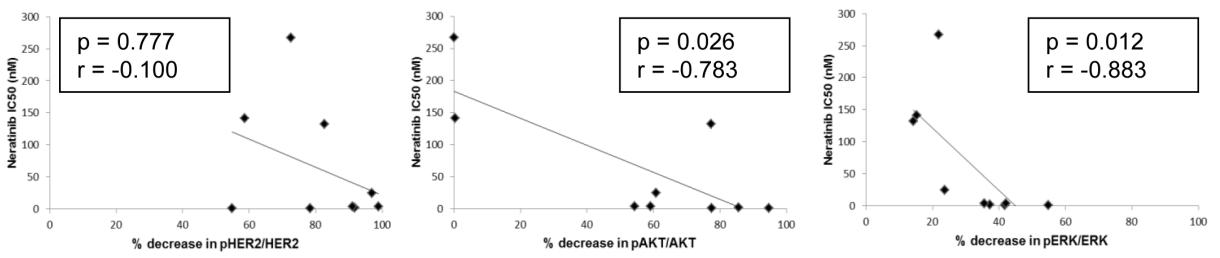

Figure 5: Levels of HER2 and pHER2 predict response to neratinib. A) Scatter plots showing the relationship between the levels of both HER2 protein and pHER2 (determined by western blotting) and neratinib sensitivity $\left(\mathrm{IC}_{50}\right)$. B) The effects of neratinib on expression and phosphorylation of HER2, Akt and ERK in HER2 positive breast cancer cell lines. C) Scatter plots showing the relationship between the neratinib $(200 \mathrm{nM})$ induced decrease in phosphorylation of HER2, Akt and ERK and neratinib sensitivity $\left(\mathrm{IC}_{50}\right)$ in 9 HER2 positive breast cancer cell lines. 


\section{DISCUSSION}

Our results showed that the combination of trastuzumab and neratinib treatment was significantly more potent at reducing cell viability than trastuzumab alone in both sensitive and acquired resistant HER2 over-expressing SKBR3 and BT474 breast cancer cells. In the trastuzumab-naïve SKBR3 and BT474 cells, acute neratinib treatment inhibited phosphorylation of EGFR, HER2, HER3 and HER4 as well as downstream pathways
A

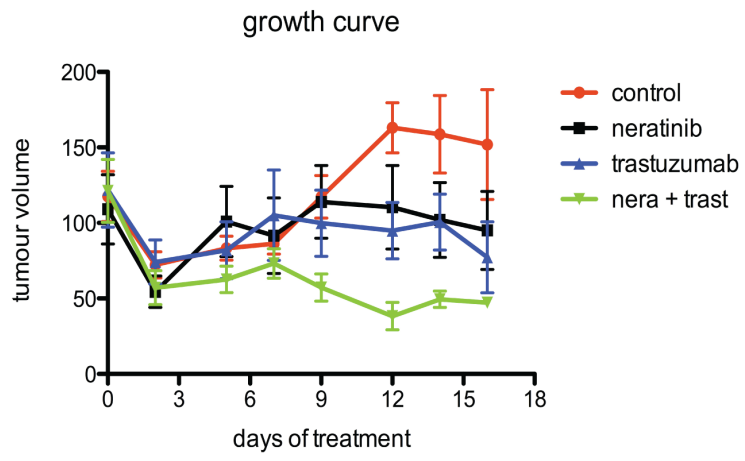

C

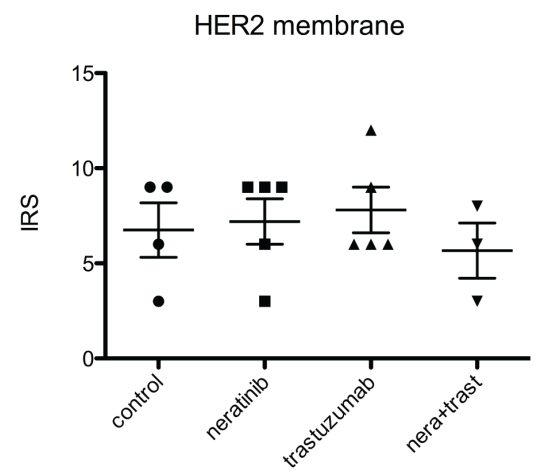

E

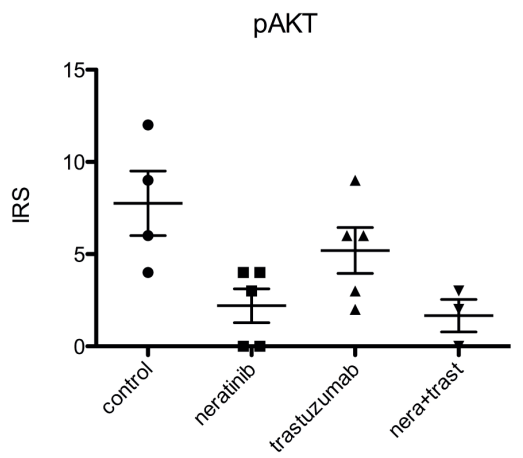

B
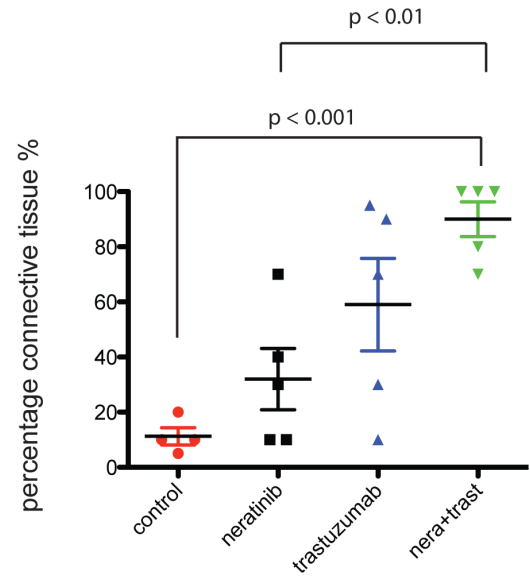

D

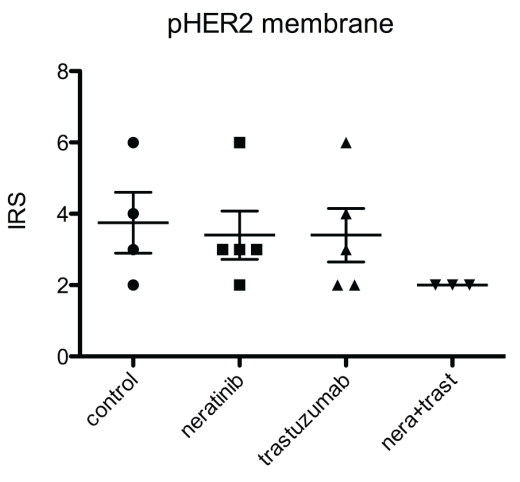

$\mathbf{F}$

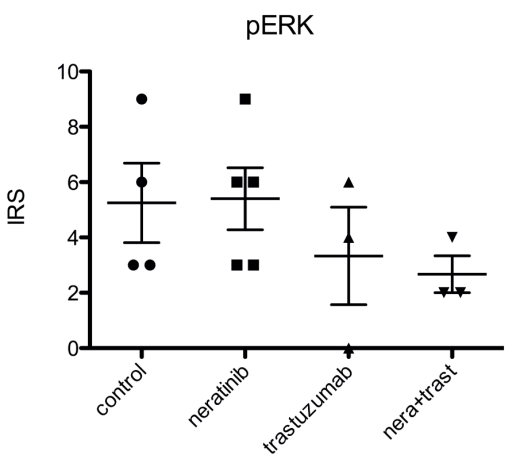

Figure 6: Combination of trastuzumab and neratinib was additive in tumor growth inhibition in BT474 xenograft model. A) Left, Mice bearing BT474 xenograft tumors were treated with either control (vehicle), neratinib, trastuzumab or their combination for 16 days. During this time, tumor size was measured in each mouse and the tumor volume calculated. B) At the end of the experiment from A, tumor samples were collected and embedded in paraffin. The slides were cut and analysed for the percentage of connective tissue per section. The differences in means of the percentage of connective tissue between the groups were analyzed by Anova with Bonferroni's multiple comparison test and statistically significant changes were indicated in the figure. C-F), Sections were cut from paraffin-embedded xenograft samples and stained for HER2, phosphorylated HER2 (pHER2), phosphorylated Akt (pAkt) and phosphorylated ERK (pERK). Sections were then scored for the intensity and percentage of staining. The IRS scoring from each condition was shown in the figures. 
ERK and Akt, reflecting its immediate inhibitory effect on the tyrosine kinase activity of all the HER receptors. In contrast, trastuzumab did not decrease phosphorylation of EGFR, HER2, HER4 and ERK, reflecting the different mechanisms of action of the drugs. The xenograft experiment also showed that the combination treatment lead to the greatest decrease in pHER2 with decreased activation of pAkt and pERK, correlating with increased efficacy compared to the single agents, in xenograft models. Although trastuzumab has been previously shown to downregulate HER2 [12, 19, 31], this effect was not seen with either trastuzumab, neratinib or the combination treatment in our xenograft study. This may be because there was a significant heterogeneity in HER2 staining between xenograft tumor areas and the dose of trastuzumab used in this study was lower than in previously reported xenograft experiments [31], which may affect the amount of HER2 downregulation and assessment [32].

Clinically, the withdrawal of trastuzumab treatment in patients who are no longer responding is controversial [33], partially due to the cost of continuing trastuzumab treatment [34]. Our data revealed that the withdrawal of trastuzumab from the trastuzumab-resistant cell lines resulted in a significantly increased cell count compared to continuation of trastuzumab treatment. Furthermore, the combination of trastuzumab and neratinib was significantly more effective than neratinib alone even in the presence of trastuzumab resistance. This is supported by recent data which showed that lapatinib in combination with trastuzumab significantly improved overall survival and progression-free survival compared to lapatinib alone despite disease progression on prior trastuzumab-based therapy $[35,36]$.

Neratinib has shown promising activity in several clinical trials, particularly in HER2 positive breast cancer patients [29, 37]. Neratinib and trastuzumab in combination with paclitaxel chemotherapy showed clinical benefit in patients who had been heavily pre-treated with anti-HER2 agents and chemotherapy, with a mean of 4 prior regimens [38]. A phase II multi-centre randomized study of neratinib in combination with weekly paclitaxel with or without trastuzumab followed by doxorubicin and cyclophosphamide (AC) as neoadjuvant therapy for women with HER2-positive locally advanced breast cancer (NSABP FB-7) is currently ongoing. As well as neratinib, other irreversible TKIs including dacomitinib (PF-00299804) and afatinib (BIBW2992) are also being tested in clinical trials. Afatinib monotherapy was shown to have promising clinical activity in extensively pretreated HER2-positive breast cancer patients who had progressed following trastuzumab treatment [39].

It has been previously shown that EGFR and HER2 inhibitors failed to suppress HER3 phosphorylation due to ligand-dependent activation of HER3 via ADAM17 through an Akt feedback loop [19, 40, 41]. This could be an important drug resistance mechanism for EGFR and HER2 inhibitors. We showed that although neratinib effectively inhibited phosphorylation of all HER receptors for up to 24 hours, reactivation of HER3 and Akt occurred within 3 days. However, the combination of trastuzumab and neratinib significantly delayed reactivation of HER3 and Akt compared to neratinib alone. In contrast a recent study showed that dual inhibition with trastuzumab and lapatinib or trastuzumab and pertuzumab does not completely eliminate HER3 function [42]. It would be interesting to determine if the reactivation of HER3 observed with neratinib is also induced by ADAM17 mediated heregulin release [19]. This possibility might be investigated using an ADAM17 inhibitor or a monoclonal antibody to HER3.

Although neratinib is a panHER inhibitor, we showed that it is selectively active in HER2 amplified compared to non-amplified breast cancer cell lines. However, some of the HER2 amplified cells listed in Supplementary Table1, including MDA-MB-361 and MDA-MB-453, have been classified as IHC 2+ or HER2 negative [43-46], as they express slightly lower levels of HER2 protein, at an expression level that is nearer to the original FDA definition of HER2 positivity [47]. Since HER2 testing results may be variable according to the methods or assays of testing [48], it is not surprising that some of these cells have been classified differently. Nevertheless, some of the moderate HER2 expressing breast cancer cells including MDA-MB-453 and MDAMB-361 show greater sensitivity to neratinib than trastuzumab. In NSABP B-41, lapatinib in combination with chemotherapy induced a greater pathological complete response than that of trastuzumab in combination with chemotherapy in breast cancer patients with IHC 2+ although the number of patients in each arm was small [49]. Thus it may be important to assess the effect of neratinib in patients whose tumors express lower levels of HER2 protein (IHC 2+).

Despite the frequent overexpression of EGFR in triple negative breast tumors and cell lines, they were less sensitive to neratinib than HER2 amplified cells. The luminal cell line, MDA-MB-175, which showed significant sensitivity to neratinib has previously been shown to be dependent on heregulin-mediated activation of HER2/HER3 signaling and are also more sensitive to pertuzumab treatment than trastuzumab [50]. In addition, neratinib but not lapatinib, has been shown to be active against HER2 somatic mutations present in about 1-3\% of HER2 negative breast cancer patients [51]. This suggests that there may be both overlapping and non-overlapping mechanisms of resistance to different HER2 inhibitors. There is a need to further understand the biomarkers that can predict response to neratinib in different breast cancer subtypes.

The levels of total HER2 protein and phosphorylated HER2 correlated with response to neratinib in the panel of 
HER2 overexpressing cell lines, similar to lapatinib [30]. HER2 protein and mRNA levels have also been shown to predict response to dacomitinib [52]. The reduction in pAkt and pERK in response to neratinib treatment was also correlated with sensitivity to neratinib. Other potential biomarkers which may be predictive of response to neratinib, and other HER2 targeted therapies, include the dimerization states of the HER receptors [53], and levels of protein tyrosine phosphatases, such as PTPN9 which has been shown to regulate EGFR and HER2 activation $[54,55]$.

Like lapatinib [30], neratinib can overcome trastuzumab resistance in cell line models of acquired trastuzumab resistance and can enhance response to trastuzumab in trastuzumab sensitive cell lines. However, neratinib also shows activity in some cell lines which are innately resistant to lapatinib which suggests that neratinib may have clinical benefit in patients who do not respond to trastuzumab and/or lapatinib. The challenge will be to identify predictive markers to select those patients with HER2 positive breast cancer who may benefit from neratinib treatment but not from trastuzumab or lapatinib. The results of this study provide a rational for clinical trials of neratinib in combination with trastuzumab and of neratinib alone (with chemotherapy) in patients whose disease has progressed on trastuzumab and/or lapatinib treatment.

\section{MATERIALS AND METHODS}

\section{Cell lines and generation of trastuzumab resistant cell lines}

SKBR3 and BT474 were obtained from CRUK London Research Institute Cell Services, and were cultured in RPMI and DMEM respectively; both were supplemented with $10 \% \mathrm{FBS}$, penicillin-streptomycin. Trastuzumab-resistant BT474 and SKBR3 cell lines were generated as previously described [19]. In addition to SKBR3 and BT474, the following panel of breast cancer cell lines was used in this study: EFM192A, HCC1419, MDA-MB-361, MDA-MB-453, SUM190, SUM225, UACC732, UACC812, UACC893, CAMA1, EFM19, KPL1, MCF7, MDA-MB-134, MDA-MB-175, MDAMB-415, T47D, ZR751, HCC1569, HCC1954, BT20, BT549, CAL51, HCC38, HCC70, HCC1143, HCC1187, HCC1395, HCC1806, HCC1937, JIMT1, MDA-MB157, MDA-MB-231, MDA-MB-468, MDA-MB-435, MDAMB-436. All cell lines used were obtained from the American Type Culture Collection (Rockville, MD, USA) unless otherwise stated. EFM192A, KPL1, EFM19 and CAL51 were supplied by the German Tissue Repository DSMZ (Braunschweig, Germany). SUM190 and SUM225 were obtained from the University of Michigan (Ann
Arbor, MI, USA). MDA-MB-134, MDA-MB-415, MDAMB-436, MDA-MB-157, UACC893 and UACC812 were cultured in L15 medium supplemented with $10 \%$ heatinactivated fetal bovine serum (FBS), $2 \mathrm{mM}$ glutamine and $1 \%$ penicillin G-streptomycin-fungizone solution (PSF) (Irvine Scientific, Santa Ana, CA, USA). DMEM (Cellgro, Manassas, VA, USA) supplemented with $10 \%$ heat-inactivated FBS and PSF (Irvine Scientific, Santa Ana, CA, USA) was used to culture CAL51 and KPL1. SUM190 and SUM225 were maintained in HAM's F12 supplemented with $5 \%$ heat inactivated FBS, PSF, $5 \mathrm{mg} /$ $\mathrm{ml}$ insulin and $1 \mathrm{mg} / \mathrm{ml}$ hydrocortisone. All other cell lines were maintained in RPMI 1640 (Cellgro) supplemented with $10 \% \mathrm{FBS}$ (heat inactivated), $2 \mathrm{mM}$ glutamine and 1 $\%$ PSF (Irvine Scientific, Santa Ana, CA, USA). All cell lines were grown in a humidified incubator at $37^{\circ} \mathrm{C}$ with 5 $\% \mathrm{CO}_{2}$ apart from MDA-MB-134, MDA-MB-157, MDAMB-175, MDA-MB-361, MDA-MB-415, MDA-MB-436, UACC812 and UACC893 which were grown at $37{ }^{\circ} \mathrm{C}$ in the absence of $\mathrm{CO}_{2}$.

Stock solutions of lapatinib $(10 \mathrm{mM})$ (Sequoia Research Products) and neratinib $(10 \mathrm{mM})$ (supplied by Pfizer) were prepared in dimethyl sulfoxide (DMSO). Trastuzumab was purchased from St Vincent's University Hospital and Oxford University Hospitals NHS Trust.

\section{Proliferation assays}

\section{Proliferation was assessed using cell counting and acid phosphatase assays.}

For cell counting experiments, cells were seeded in duplicate at $2-3 \times 10^{4}$ cells per well, depending on the cell line, in 24 well plates. The cells were treated for 5 days unless otherwise stated. On the concluding day of the experiments, the cells were washed with phosphate buffered saline (PBS) before trypsinization and counted using ISOTON solution on the Coulter Z2 particle counter (Beckham Coulter, Inc). Growth inhibition relative to control treated cells was determined. The log of drug concentration was then plotted against the log growth inhibition and $\mathrm{IC}_{50}$ values were calculated using linear regression analysis as previously described [30].

For the acid phosphatase assay, $5 \times 10^{4}$ cells/well for MDA-MB-361 cells, and $3 \times 10^{4}$ cells/well for the other cell lines were seeded in triplicate 96 -well plates. Following overnight incubation at $37^{\circ} \mathrm{C}$, drugs were added at the appropriate concentrations and incubated for 5 days at $37^{\circ} \mathrm{C}$. Cells were washed once with PBS and acid phosphatase substrate $(7.25 \mathrm{mM}$ p-nitrophenyl-phosphate (Sigma) in sodium acetate buffer) was added to each well and incubated at $37{ }^{\circ} \mathrm{C}$ for 1 hour. The reaction was stopped by adding $50 \mu 11 \mathrm{M} \mathrm{NaOH}$ and absorbance was read at $405 \mathrm{~nm}$ with $620 \mathrm{~nm}$ as the reference wavelength. 


\section{Xenograft experiment}

The flank of BALC/nu/nu mice was injected with $10^{7}$ BT474 cells in Matrigel and left to grow (under the project license PPL 30/2771). Mice were provided with $5 \mu \mathrm{g} / \mathrm{ml}$ oestradiol in the drinking water for the duration of the experiment. When tumors reached an average size of $125 \mathrm{~mm}^{3}$, the mice were divided into 4 groups, keeping average tumor size similar between groups. The control group of 4 mice was treated with vehicle $(0.5 \%$ methocellulose $-0.4 \%$ polysorbate- 80 (Tween 80 )) by gavage daily and sterile PBS intraperitoneally (IP) twice weekly. The treatment groups consisted of 5 mice, treated with: (i) vehicle containing neratinib $10 \mathrm{mg} / \mathrm{kg}$ by gavage daily and IP PBS twice a week; (ii) trastuzumab $10 \mathrm{mg} /$ $\mathrm{kg}$ (twice weekly IP) and vehicle by gavage daily; (iii) trastuzumab $10 \mathrm{mg} / \mathrm{kg}$ by IP twice a week with neratinib $(10 \mathrm{mg} / \mathrm{kg})$ by gavage daily. The treatment continued for 17 days (5 trastuzumab treatments) and the mice were sacrificed 3 hours after the last neratinib treatment. Tumours were weighed and collected in $4 \%$ formalin to fix over night at $4{ }^{\circ} \mathrm{C}$. The samples were then embedded in paraffin for immunohistochemical analysis.

\section{Western Blotting}

\section{Neratinib dose escalation studies in naïve and acquired resistant SKBR3 and BT474 cells}

SKBR3 and BT474 cells were seeded and left to adhere overnight. Cells were treated as indicated before they were placed on ice and washed with PBS. Lysis buffer (10 mM EDTA, $20 \mathrm{mM}$ Tris pH 7.5, $150 \mathrm{mM}$ $\mathrm{NaCl}, 10 \mathrm{mM} \mathrm{Na}_{2} \mathrm{P}_{2} \mathrm{O}_{7}$ and $100 \mathrm{mM} \mathrm{NaF}$ with $1 \%$ Triton $\mathrm{X}$ and 1:100 protease inhibitor cocktail) was added to the cells and the cells scraped off the plates. Samples were centrifuged at $4^{\circ} \mathrm{C}$ to remove the insoluble cell pellets. Bradford Protein Assay was then performed to determine protein concentration. Equal amounts of protein sample were prepared in $4 \mathrm{X}$ SDS with $10 \%$ beta-mercaptoethanol, boiled for 10 minutes at $95^{\circ} \mathrm{C}$. Samples were then loaded into a NuPage $4-12 \%$ gel and ran at $100 \mathrm{~V}$ for 15 minutes then $130 \mathrm{~V}$ until completion. The proteins were semi-dry transferred to a PVDF membrane for two hours at $12 \mathrm{~V}$. The membrane was blocked in 3\% BSA in PBS-Tween $(0.2 \%)$ for a minimum of one hour. The membrane was then incubated with primary antibody in $3 \%$ BSA in PBSTween overnight at $4^{\circ} \mathrm{C}$. All antibodies were purchased from Cell Signalling Technologies. The membrane was then washed four times with $1 \%$ milk in PBS-Tween $(0.2 \%)$ at room temperature and incubated with secondary antibody in $5 \%$ milk PBS-Tween $(0.2 \%)$ for one hour before washing four times in 1\% milk PBS-Tween. Bands were then visualized and the blot developed using an enhanced chemiluminescent system (ECL, GE Heathcare).
Bands were quantified using ImageJ software.

\section{Pharmacodynamic biomarkers of neratinib response in a panel of cell lines}

After neratinib treatment for $24 \mathrm{~h}$, cells were washed with PBS and lysed in RIPA buffer (Sigma) containing protease inhibitors, $1 \mathrm{mM}$ phenylmethylsulfonyl fluoride (PMSF) and $1 \mathrm{mM}$ sodium orthovanadate. After 20 min incubation on ice, lysate was passed through a 21-gauge needle and centrifuged at 10,000 g for $5 \mathrm{~min}$ at $4^{\circ} \mathrm{C}$. Protein quantification was carried out using the bicinchoninic acid assay (Pierce).

Forty $\mu \mathrm{g}$ of protein were solubilized in sample buffer $(250 \mathrm{mM}$ Tris- $\mathrm{HCl} ; 10 \%$ sodium dodecyl sulphate (SDS); 5\% beta-mercaptoethanol; 30\% glycerol; $0.02 \%$ bromophenol blue), heated to $95{ }^{\circ} \mathrm{C}$ for 5 min and separated using $7.5 \%$ polyacrylamide gels (Lonza). Proteins were transferred to Hybond enhanced chemiluminescence nitrocellulose membrane (Amersham, Biosciences, Buckinghamshire, UK). The membrane was blocked with $5 \%$ milk in PBS- $0.1 \%$ Tween at room temperature for $1 \mathrm{~h}$. After overnight incubation at $4^{\circ} \mathrm{C}$ with primary antibody (anti-HER2, Calbiochem, all other antibodies from Cell Signaling Technology) in 5\% blocking solution milk in PBS- $0.1 \%$ Tween, three washes with PBS- $-0.1 \%$ Tween were carried out, followed by incubation at room temperature with secondary antibody in 5\% blocking solution milk in PBS- $0.1 \%$ Tween for 1 hour. Following three washes with PBS- $0.1 \%$ Tween and one PBS wash, protein bands were detected using Luminol (Santa Cruz Biotechnology Inc., Santa Cruz, CA).

\section{Immunohistochemisty and immunoreactive (IRS) scoring}

Formalin-fixed BT474 xenograft samples were embedded in paraffin and $4 \mu \mathrm{m}$ thick sections were cut for immunohistochemical staining. The sections were dewaxed and rehydrated prior to antigen retrieval using Tris/EDTA at pH9 for HER2 and phosho-HER2, or citrate buffer at pH6 for the other antibodies. Sections were blocked using horse serum (Vector laboratories) overnight at $4^{\circ} \mathrm{C}$. The following day, sections were incubated with primary antibodies for 2 hours at room temperature, followed by 3 washes with PBS. The sections were then incubated with a horseradish peroxidise-coupled antirabbit secondary antibody (Vector laboratories) for 30 minutes at room temperature. Visualization of staining was performed using a diaminobenzidine (DAB) peroxidase substrate (Vector Laboratories). Counterstaining was performed using Haemocytoxin prior to the mounting using aqueous-based mounting media (Aquatex). Levels of staining were scored blindly. The scoring criteria is composite score based on staining intensity (SI) and percentage of positive cells (PP) using the formula IRS $=\mathrm{SI} \times \mathrm{PP}$. The staining intensity (SI) was determined as 
$0=$ negative $; 1=$ weak $2=$ moderate; and $3=$ strong and the percentage of positive cells (PP) was defined as $0,<1 \% ; 1,1 \%-10 \% ; 2,11 \%-50 \% ; 3,51 \%-80 \%$; and 4 , $>80 \%$ positive cells.

\section{Statistical analysis}

Mann-Whitney $U$ test was used to investigate the association between response to neratinib and breast cancer cell line subtype. The differences in the means between different conditions or groups $(n>2)$ were analysed by Anova with Bonferroni's multiple comparison test and $p<0.05$ was taken to be statistically significant. Relationships between neratinib response and HER2, pHER2, p95, EGFR, HER3, Akt, ERK, PTEN, PI3K and ER (from O'Brien et al [30]) were examined using the Spearman's Rank correlation and Mann-Whitney $U$ test on StatView for Windows (version 5.0.1) (SAS Institute, Inc).

\section{FUNDING}

Dr. Anthony Kong and his lab members are supported by Breakthrough Breast Cancer through Holbeck Charitable trust. Prof John Crown and colleagues in Molecular Therapeutics for Cancer Ireland acknowledge support from the Health Research Board, Ireland (CSA/2007/11), Science Foundation Ireland (08/ SRC/B1410) and the Cancer Clinical Research Trust. We also thank the BREAST-PREDICT (CCRC13GAL) programme of the Irish Cancer Society for funding this work. Dr Alexandra Canonici was a recipient of the Claude Rozé Prize from the CECED (Club d'Etudes des Cellules Epithéliales Digestives). Other funders supporting the co-authors and core facilities in Oxford include Cancer Research UK, Medical Research Council, Oxford Biomedical Research Centre, Oxford Experimental Cancer Medicine Centre and Cancer Research UK Oxford Cancer Research Centre.

\section{ACKNOWLEDGEMENT}

We are grateful to all the members of Professor Adrian Harris' lab for their help and advice.

\section{REFERENCES}

1. Citri A, Yarden Y. EGF-ERBB signalling: towards the systems level. Nat Rev Mol Cell Biol. 2006; 7:505-516.

2. Olayioye MA, Neve RM, Lane HA, Hynes NE. The ErbB signaling network: receptor heterodimerization in development and cancer. EMBO J. 2000; 19:3159-3167.

3. Cho HS, Mason K, Ramyar KX, Stanley AM, Gabelli SB, Denney DW, Jr., Leahy DJ. Structure of the extracellular region of HER2 alone and in complex with the Herceptin Fab. Nature. 2003; 421:756-760.
4. Graus-Porta D, Beerli RR, Daly JM, Hynes NE. ErbB-2, the preferred heterodimerization partner of all ErbB receptors, is a mediator of lateral signaling. EMBO J. 1997; 16:16471655.

5. Lee-Hoeflich ST, Crocker L, Yao E, Pham T, Munroe X, Hoeflich KP, Sliwkowski MX, Stern HM. A central role for HER3 in HER2-amplified breast cancer: implications for targeted therapy. Cancer Res. 2008; 68:5878-5887.

6. Baselga J, Swain SM. Novel anticancer targets: revisiting ERBB2 and discovering ERBB3. Nat Rev Cancer. 2009; 9:463-475.

7. Yarden Y, Sliwkowski MX. Untangling the ErbB signalling network. Nat Rev Mol Cell Biol. 2001; 2:127-137.

8. Slamon DJ, Clark GM, Wong SG, Levin WJ, Ullrich A, McGuire WL. Human breast cancer: correlation of relapse and survival with amplification of the HER-2/neu oncogene. Science. 1987; 235:177-182.

9. Slamon DJ, Godolphin W, Jones LA, Holt JA, Wong SG, Keith DE, Levin WJ, Stuart SG, Udove J, Ullrich A, et al. Studies of the HER-2/neu proto-oncogene in human breast and ovarian cancer. Science. 1989; 244:707-712.

10. Piccart-Gebhart MJ, Procter M, Leyland-Jones B, Goldhirsch A, Untch M, Smith I, Gianni L, Baselga J, Bell R, Jackisch C, Cameron D, Dowsett M, Barrios CH, Steger G, Huang CS, Andersson M et al. Trastuzumab after adjuvant chemotherapy in HER2-positive breast cancer. N Engl J Med. 2005; 353:1659-1672.

11. Romond EH, Perez EA, Bryant J, Suman VJ, Geyer CE, Jr., Davidson NE, Tan-Chiu E, Martino S, Paik S, Kaufman PA, Swain SM, Pisansky TM, Fehrenbacher L, Kutteh LA, Vogel VG, Visscher DW et al. Trastuzumab plus adjuvant chemotherapy for operable HER2-positive breast cancer. N Engl J Med. 2005; 353:1673-1684.

12. Sliwkowski MX, Lofgren JA, Lewis GD, Hotaling TE, Fendly BM, Fox JA. Nonclinical studies addressing the mechanism of action of trastuzumab (Herceptin). Semin Oncol. 1999; 26:60-70.

13. Vogel CL, Cobleigh MA, Tripathy D, Gutheil JC, Harris LN, Fehrenbacher L, Slamon DJ, Murphy M, Novotny WF, Burchmore M, Shak S, Stewart SJ, Press M. Efficacy and safety of trastuzumab as a single agent in first-line treatment of HER2-overexpressing metastatic breast cancer. J Clin Oncol. 2002; 20:719-726.

14. Nagata Y, Lan KH, Zhou X, Tan M, Esteva FJ, Sahin AA, Klos KS, Li P, Monia BP, Nguyen NT, Hortobagyi GN, Hung MC, Yu D. PTEN activation contributes to tumor inhibition by trastuzumab, and loss of PTEN predicts trastuzumab resistance in patients. Cancer Cell. 2004; 6:117-127.

15. Berns K, Horlings HM, Hennessy BT, Madiredjo M, Hijmans EM, Beelen K, Linn SC, Gonzalez-Angulo AM, Stemke-Hale K, Hauptmann M, Beijersbergen RL, Mills GB, van de Vijver MJ, Bernards R. A functional genetic approach identifies the PI3K pathway as a major 
determinant of trastuzumab resistance in breast cancer. Cancer Cell. 2007; 12:395-402.

16. Arribas J, Baselga J, Pedersen K, Parra-Palau JL. p95HER2 and breast cancer. Cancer Res. 2011; 71:1515-1519.

17. Lu Y, Zi X, Zhao Y, Mascarenhas D, Pollak M. Insulinlike growth factor-I receptor signaling and resistance to trastuzumab (Herceptin). J Natl Cancer Inst. 2001; 93:18521857.

18. Shattuck DL, Miller JK, Carraway KL, 3rd, Sweeney C. Met receptor contributes to trastuzumab resistance of Her2overexpressing breast cancer cells. Cancer Res. 2008; 68:1471-1477.

19. Gijsen M, King P, Perera T, Parker PJ, Harris AL, Larijani $\mathrm{B}$, Kong A. HER2 phosphorylation is maintained by a PKB negative feedback loop in response to anti-HER2 herceptin in breast cancer. PLoS Biol. 2010; 8:e1000563.

20. Cufi S, Vazquez-Martin A, Oliveras-Ferraros C, CorominasFaja B, Urruticoechea A, Martin-Castillo B, Menendez JA. Autophagy-related gene 12 (ATG12) is a novel determinant of primary resistance to HER2-targeted therapies: utility of transcriptome analysis of the autophagy interactome to guide breast cancer treatment. Oncotarget. 2012; 3:16001614.

21. Cufi S, Corominas-Faja B, Vazquez-Martin A, OliverasFerraros C, Dorca J, Bosch-Barrera J, Martin-Castillo B, Menendez JA. Metformin-induced preferential killing of breast cancer initiating CD44+CD24-/low cells is sufficient to overcome primary resistance to trastuzumab in HER2+ human breast cancer xenografts. Oncotarget. 2012; 3:395398.

22. Wilken JA, Maihle NJ. Primary trastuzumab resistance: new tricks for an old drug. Ann N Y Acad Sci. 2010; 1210:5365.

23. Geyer CE, Forster J, Lindquist D, Chan S, Romieu CG, Pienkowski T, Jagiello-Gruszfeld A, Crown J, Chan A, Kaufman B, Skarlos D, Campone M, Davidson N, Berger M, Oliva C, Rubin SD et al. Lapatinib plus capecitabine for HER2-positive advanced breast cancer. N Engl J Med. 2006; 355:2733-2743.

24. Baselga J, Bradbury I, Eidtmann H, Di Cosimo S, de Azambuja E, Aura C, Gomez H, Dinh P, Fauria K, Van Dooren V, Aktan G, Goldhirsch A, Chang TW, Horvath Z, Coccia-Portugal M, Domont J et al. Lapatinib with trastuzumab for HER2-positive early breast cancer (NeoALTTO): a randomised, open-label, multicentre, phase 3 trial. Lancet. 2012; 379:633-640.

25. Untch M, Loibl S, Bischoff J, Eidtmann H, Kaufmann M, Blohmer JU, Hilfrich J, Strumberg D, Fasching PA, Kreienberg R, Tesch H, Hanusch C, Gerber B, Rezai M, Jackisch C, Huober J et al. Lapatinib versus trastuzumab in combination with neoadjuvant anthracycline-taxane-based chemotherapy (GeparQuinto, GBG 44): a randomised phase 3 trial. Lancet Oncol. 2012; 13:135-144.

26. Wissner A, Mansour TS. The development of HKI-272 and related compounds for the treatment of cancer. Arch Pharm (Weinheim). 2008; 341:465-477.

27. Rabindran SK, Discafani CM, Rosfjord EC, Baxter M, Floyd MB, Golas J, Hallett WA, Johnson BD, Nilakantan R, Overbeek E, Reich MF, Shen R, Shi X, Tsou HR, Wang YF, Wissner A. Antitumor activity of HKI-272, an orally active, irreversible inhibitor of the HER-2 tyrosine kinase. Cancer Res. 2004; 64:3958-3965.

28. Bottle A, Tsang C, Parsons C, Majeed A, Soljak M, Aylin P. Association between patient and general practice characteristics and unplanned first-time admissions for cancer: observational study. Br J Cancer. 2012.

29. Bose P, Ozer H. Neratinib: an oral, irreversible dual EGFR/ HER2 inhibitor for breast and non-small cell lung cancer. Expert Opin Investig Drugs. 2009; 18:1735-1751.

30. O'Brien NA, Browne BC, Chow L, Wang Y, Ginther C, Arboleda J, Duffy MJ, Crown J, O’Donovan N, Slamon DJ. Activated phosphoinositide 3-kinase/AKT signaling confers resistance to trastuzumab but not lapatinib. Mol Cancer Ther. 2010; 9:1489-1502.

31. Kramer-Marek G, Gijsen M, Kiesewetter DO, Bennett R, Roxanis I, Zielinski R, Kong A, Capala J. Potential of PET to predict the response to trastuzumab treatment in an ErbB2-positive human xenograft tumor model. J Nucl Med. 2012; 53:629-637.

32. Capala J, Kong A, Kramer-Marek G, Gijsen M. Reply. J Nucl Med. 2012.

33. Montemurro F, Faggiuolo R, Redana S, Donadio M, Minischetti M, Durando A, Vietti-Ramus G, Buosi R, Aglietta M. Continuation of trastuzumab beyond disease progression. J Clin Oncol. 2005; 23:2866-2868; discussion 2868-2869.

34. Matter-Walstra KW, Dedes KJ, Schwenkglenks M, Brauchli P, Szucs TD, Pestalozzi BC. Trastuzumab beyond progression: a cost-utility analysis. Ann Oncol. 2010; 21:2161-2168.

35. Blackwell KL, Burstein HJ, Storniolo AM, Rugo H, Sledge G, Koehler M, Ellis C, Casey M, Vukelja S, Bischoff J, Baselga J, O'Shaughnessy J. Randomized study of Lapatinib alone or in combination with trastuzumab in women with ErbB2-positive, trastuzumab-refractory metastatic breast cancer. J Clin Oncol. 2010; 28:1124-1130.

36. Blackwell KL, Burstein HJ, Storniolo AM, Rugo HS, Sledge G, Aktan G, Ellis C, Florance A, Vukelja S, Bischoff J, Baselga J, O'Shaughnessy J. Overall survival benefit with lapatinib in combination with trastuzumab for patients with human epidermal growth factor receptor 2-positive metastatic breast cancer: final results from the EGF104900 Study. J Clin Oncol. 2012; 30:2585-2592.

37. Awada A, Dirix L, Manso Sanchez L, Xu B, Luu T, Dieras V, Hershman DL, Agrapart V, Ananthakrishnan R, Staroslawska E. Safety and efficacy of neratinib (HKI-272) plus vinorelbine in the treatment of patients with ErbB2positive metastatic breast cancer pretreated with anti-HER2 
therapy. Ann Oncol. 2012.

38. Jankowitz RC, Abraham J, Tan AR, Limentani SL, Adamson LM, Buyse ME, Jacobs SA, Wolmark N. A phase I dose-escalation study evaluating weekly paclitaxel with neratinib and trastuzumab in women with metastatic HER2positive breast cancer, NSABP FB-8. J Clin Oncol 30, 2012 (suppl; abstr 611). 2012.

39. Lin NU, Winer EP, Wheatley D, Carey LA, Houston S, Mendelson D, Munster P, Frakes L, Kelly S, Garcia AA, Cleator S, Uttenreuther-Fischer M, Jones H, Wind S, Vinisko R, Hickish T. A phase II study of afatinib (BIBW 2992), an irreversible ErbB family blocker, in patients with HER2-positive metastatic breast cancer progressing after trastuzumab. Breast Cancer Res Treat. 2012; 133:10571065.

40. Sergina NV, Rausch M, Wang D, Blair J, Hann B, Shokat KM, Moasser MM. Escape from HER-family tyrosine kinase inhibitor therapy by the kinase-inactive HER3. Nature. 2007; 445:437-441.

41. Kong A, Calleja V, Leboucher P, Harris A, Parker PJ, Larijani B. HER2 oncogenic function escapes EGFR tyrosine kinase inhibitors via activation of alternative HER receptors in breast cancer cells. PLoS ONE. 2008; 3:e2881.

42. Garrett J, Sutton CR, Kuba MG, Cook RS, Arteaga CL. Dual blockade of HER2 in HER2-overexpressing tumor cells does not completely eliminate HER3 function. Clin Cancer Res. 2012.

43. Vranic S, Gatalica Z, Wang ZY. Update on the molecular profile of the MDA-MB-453 cell line as a model for apocrine breast carcinoma studies. Oncol Lett. 2011; 2:1131-1137.

44. DeFazio-Eli L, Strommen K, Dao-Pick T, Parry G, Goodman L, Winslow J. Quantitative assays for the measurement of HER1-HER2 heterodimerization and phosphorylation in cell lines and breast tumors: applications for diagnostics and targeted drug mechanism of action. Breast Cancer Res. 2011; 13:R44.

45. Rhodes A, Jasani B, Anderson E, Dodson AR, Balaton AJ. Evaluation of HER-2/neu immunohistochemical assay sensitivity and scoring on formalin-fixed and paraffinprocessed cell lines and breast tumors: a comparative study involving results from laboratories in 21 countries. Am J Clin Pathol. 2002; 118:408-417.

46. Juranic ZD, Borojevic N, Jovanovic D, Stanojevic-Bakic N, Zizak Z, Neskovic-Konstantinovic Z, Saric M, Stanojkovic T, Raonic T, Milosevic D. Effects of X-ray irradiation on the overexpression of HER-2/Erb-B2 on breast cancer cell lines. J Exp Clin Cancer Res. 2004; 23:675-680.

47. Wolff AC, Hammond ME, Schwartz JN, Hagerty KL, Allred DC, Cote RJ, Dowsett M, Fitzgibbons PL, Hanna WM, Langer A, McShane LM, Paik S, Pegram MD, Perez EA, Press MF, Rhodes A et al. American Society of Clinical Oncology/College of American Pathologists guideline recommendations for human epidermal growth factor receptor 2 testing in breast cancer. J Clin Oncol.
$2007 ; 25: 118-145$.

48. Allison M. The HER2 testing conundrum. Nat Biotechnol. 2010; 28:117-119.

49. Robidoux A, Tang G, Rastogi P, al. e. Evaluation of lapatinib as a component of neoadjuvant therapy for HER2+ operable breast cancer: NSABP protocol B-41. J Clin Oncol 2012; (Suppl):LBA506.

50. Schaefer G, Fitzpatrick VD, Sliwkowski MX. Gammaheregulin: a novel heregulin isoform that is an autocrine growth factor for the human breast cancer cell line, MDAMB-175. Oncogene. 1997; 15:1385-1394.

51. Bose R, Kavuri SM, Searleman AC, Shen W, Shen D, Koboldt DC, Monsey J, Goel N, Aronson AB, Li S, Ma CX, Ding L, Mardis ER, Ellis MJ. Activating HER2 mutations in HER2 gene amplification negative breast cancer. Cancer Discov. 2013; 3:224-237.

52. Kalous O, Conklin D, Desai AJ, O’Brien NA, Ginther C, Anderson L, Cohen DJ, Britten CD, Taylor I, Christensen JG, Slamon DJ, Finn RS. Dacomitinib (PF-00299804), an Irreversible Pan-HER Inhibitor, Inhibits Proliferation of HER2-Amplified Breast Cancer Cell Lines Resistant to Trastuzumab and Lapatinib. Mol Cancer Ther. 2012; 11:1978-1987.

53. Waterhouse BR, Gijsen M, Barber PR, Tullis ID, Vojnovic B, Kong A. Assessment of EGFR/HER2 dimerization by FRET-FLIM utilizing Alexa-conjugated secondary antibodies in relation to targeted therapies in cancers. Oncotarget. 2011; 2:728-736.

54. Aceto N, Bentires-Alj M. Targeting protein-tyrosine phosphatases in breast cancer. Oncotarget. 2012; 3:514-515.

55. Yuan T, Wang Y, Zhao ZJ, Gu H. Protein-tyrosine phosphatase PTPN9 negatively regulates ErbB2 and epidermal growth factor receptor signaling in breast cancer cells. J Biol Chem. 2010; 285:14861-14870. 